\title{
Developmental Psychology
}

\section{Type of Iconicity Matters in the Vocabulary Development of Signing Children}

Gerardo Ortega, Beyza Sümer, and Aslı Özyürek

Online First Publication, November 3, 2016. http://dx.doi.org/10.1037/dev0000161

CITATION

Ortega, G., Sümer, B., \& Özyürek, A. (2016, November 3). Type of Iconicity Matters in the Vocabulary Development of Signing Children. Developmental Psychology. Advance online publication. http://dx.doi.org/10.1037/dev0000161 


\title{
Type of Iconicity Matters in the Vocabulary Development of Signing Children
}

\author{
Gerardo Ortega, Beyza Sümer, and Aslı Özyürek \\ Radboud University and Max Planck Institute for Psycholinguistics
}

\begin{abstract}
Recent research on signed as well as spoken language shows that the iconic features of the target language might play a role in language development. Here, we ask further whether different types of iconic depictions modulate children's preferences for certain types of sign-referent links during vocabulary development in sign language. Results from a picture description task indicate that lexical signs with 2 possible variants are used in different proportions by deaf signers from different age groups. While preschool and school-age children favored variants representing actions associated with their referent (e.g., a writing hand for the sign PEN), adults preferred variants representing the perceptual features of those objects (e.g., upward index finger representing a thin, elongated object for the sign PEN). Deaf parents interacting with their children, however, used action- and perceptual-based variants in equal proportion and favored action variants more than adults signing to other adults. We propose that when children are confronted with 2 variants for the same concept, they initially prefer action-based variants because they give them the opportunity to link a linguistic label to familiar schemas linked to their action/motor experiences. Our results echo findings showing a bias for action-based depictions in the development of iconic co-speech gestures suggesting a modality bias for such representations during development.
\end{abstract}

Keywords: sign language, iconicity, vocabulary development, action, child-directed communication

Supplemental materials: http://dx.doi.org/10.1037/dev0000161.supp

Regardless of whether they are expressed in the aural-oral (speech) or visual-manual channel (sign, gesture), languages can "mimic" the acoustic or visual properties of their referents (Dingemansec, Blasi, Lupyan, Christiansen, \& Monaghan, 2015; Perniss, Thompson, \& Vigliocco, 2010; Vigliocco, Perniss, \& Vinson, 2014). That is, some linguistic forms, rather than having an arbitrary relationship with the referent, exhibit direct iconic mappings by means of perceptuomotor analogies between form and meaning. In spoken languages, words can have different motivated links with the sounds produced by their referent, as in the case of onomatopoeia (e.g., moo for "cow"), ideophones (e.g., gblogblogblo in Siwu for "bubbling"), or in mimetic verbs (e.g., in Japanese the sounds $/ \mathrm{g} /, / \mathrm{k} /$, and $/ \mathrm{r} /$ generate words associated to rotation;

Gerardo Ortega, Beyza Sümer, and Aslı Özyürek, Centre for Language Studies, Radboud University and Max Planck Institute for Psycholinguistics.

This work has been supported by a European Research Council Starting Grant (ERC) awarded to Aslı Özyürek. We thank Şule Kibar and Sevinç Akın, the deaf research assistants who helped with the coding and classification of the lexical signs. We would also like to express our gratitude to all the parents and their children, without whom this project would not have been possible. Special thanks go to Trevor Johnston and Adam Schembri for their feedback on earlier versions of the manuscript.

Correspondence concerning this article should be addressed to Gerardo Ortega, Center for Language Studies, Radboud University, and Max Planck Institute for Psycholinguistics, Wundtlaan 1, Kamer 312, Nijmegen, the Netherlands 6525XD. E-mail: gerardo.ortega@mpi.nl
Assaneo, Nichols, \& Trevisan, 2011; Dingemanse, 2011; Oda, 2000). In addition to iconicity in speech, spoken languages are usually accompanied by the so-called iconic gestures, which are manual depictions of the objects and events described in cooccurring speech (e.g., a curved handshape moving toward the mouth accompanying the verb drink; McNeill, 1992). The sign languages of the deaf communities stand out for their prevalence of a large number of linguistic labels whose forms are motivated by the features of their referents (Cuxac, 1999; Emmorey, 2014; Klima \& Bellugi, 1979; Padden, Hwang, Lepic, \& Seegers, 2015; Perniss et al., 2010; Pietrandrea, 2002; Taub, 2001). Furthermore, a myriad of empirical studies employing linguistic, ethnographic, behavioral and neurological methods has produced strong evidence showing that iconicity is a common feature of spoken and signed languages (Dingemanse et al., 2015; Vigliocco et al., 2014).

Recent research on language development has found modulating effects of such iconic labels during spoken and signed language learning. Infants across different cultures are sensitive to the iconic properties of words irrespectively of whether they are present in their own language or not (Revill, Namy, Defife, \& Nygaard, 2014; Yoshida, 2012), and have been found to facilitate phonological and lexical development (Imai \& Kita, 2014; Imai, Kita, Nagumo, \& Okada, 2008; Kantartzis, Imai, \& Kita, 2011; Laing, 2014). Iconicity also influences caregivers' communication, in that it shapes the form of child-directed communication compared with adult-adult interactions (Akita, 2009; Yoshida, 2012). Regarding sign languages, traditional accounts concluded that iconicity does not play a role in sign acquisition (Meier, Mauk, Cheek, \& Moreland, 2008; Newport \& Meier, 1985; Orlansky \& Bonvillian, 
1984). However, more recent studies show that the first signs acquired by deaf children are iconic in nature (Thompson, Vinson, Woll, \& Vigliocco, 2012). These findings provide converging evidence for the claim that linguistic forms that are more grounded in perceptual and motoric experience (i.e., iconic) are easier to learn, leading caregivers to modify their child-directed interactions accordingly (Imai \& Kita, 2014; Perniss \& Vigliocco, 2014).

This research, however, has not taken into account the different ways communicative signals might be linked to their referents, but has so far only compared iconic labels in general with arbitrary ones. Evidence from spoken and signed languages shows that iconicity is not a binary property, but rather that it comes in different forms and degrees, and exploits different possible types of perceptuomotor analogies (Dingemanse et al., 2015; Klima \& Bellugi, 1979; Perniss, Zwitserlood, \& Özyürek, 2015). Here, we ask whether the different ways in which form and referent are linked in iconic signs might play a role in children's preferences in vocabulary development as well as in child-directed communication.

\section{Iconicity and Lexical Variation in Sign Languages}

Iconic signs may represent physical aspects of an object, manner and path of motion, as well as spatial distribution and relationship between entities in a motivated way (Emmorey, 2001; Klima \& Bellugi, 1979; Perniss, Zwitserlood, et al., 2015; Pietrandrea, 2002; Taub, 2001). The analogue building model (Taub, 2001) proposes that iconic signs derive from our conceptual knowledge of an entity (e.g., an eagle flies, and has wings and a curved beak), the selection of one its features (e.g., the wings) and its schematization into a manual phonology (e.g., the sign EAGLE in many sign languages consists of flapping the arms). Expanding on this model, Emmorey (2014) put forward the notion of iconicity as structure mapping, which posits that a phonological representation of an iconic sign may overlap in varying degrees with a conceptual visual representation of a concept and this will influence linguistic development and processing. Iconic signs have been argued to make up two thirds of a signed lexicon (Boyes-Braem, 1986) and the phonological structure of at least $50 \%$ to $60 \%$ of signs may be traced back to the visual features of a referent (Pietrandrea, 2002). As such, sign languages are unique in the large number of motivated structures within a conventionalized linguistics system.

At the lexical level, our main focus here, signs exploit a range of iconic depicting strategies to represent the same referent by showing actions associated with an object and how it is manipulated (i.e., handling), outlining its shape (i.e., tracing), or using a body part to represent its dimensions (i.e., instrument; Padden et al., 2014, 2015). ${ }^{1}$ The possibility to depict a referent in multiple ways results in the presence of more than one lexical variant for the same concept. In British Sign Language (BSL), for example, multiple lexical variants have been documented for a range of common concepts such as colors, countries, and numbers (Stamp et al., 2014). Lexical variation for objects may involve, among others, two types: one representing a motor action associated with an object through manipulation or interaction with it (action-based signs), and the other representing its perceptual features (perceptual-based signs). In Turkish Sign Language (Türk Issaret Dili [TID]) and Australian Sign Language (Auslan), for example, the action-based variant BED represents someone lying on a

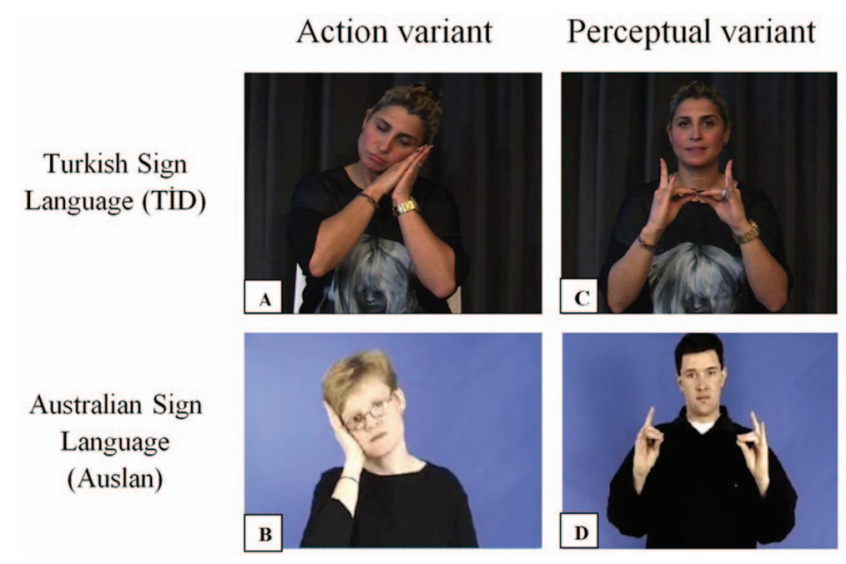

Figure 1. Action and perceptual-based variants BED in Turkish Sign Language (TID) and Australian Sign Language (Auslan). The action variants (A and B) represent a person lying on a pillow, whereas the perceptual variants $(C$ and $D)$ represent the bed head and mattress. The authors received signed consent from the person in images $1 \mathrm{~A}$ and $1 \mathrm{C}$ to be published in this article (Copyright 2016 by Asli Özyürek). Images 1B and 1D adapted with permission from the Auslan SignBank (http://www .auslan.org.au/; Copyright 2016 by Auslan SignBank). See the online article for the color version of this figure.

pillow (Figure 1A, B), whereas the perceptual-based variant represents a mattress and bedhead (Figure 1C, D). These variants stand for the same concept and differ only in their iconic motivation, ${ }^{2}$ and have been explained further under the notion of iconicity as structure mapping (Emmorey, 2014). In this notion, even though the structure of both lexical variants is motivated by the same referent, they differ in the level of abstraction. In action variants, the sign articulators (i.e., body, head, and hands) represent the body parts executing an action associated with the referent in a one-to-one manner (e.g., body and hands are configured in a similar way as a person would when lying on a bed). This is not the case for perceptual signs because the hands do not represent the hands but rather the parts of an object (e.g., a bed's surface and its legs), and as such, they require a higher level of abstraction.

Iconic lexical variants are common in sign languages, but it is unclear what factors drive lexical choice during signing. Experimental studies with adult signers have shown that sign languages do not use a single variant exclusively, but merely a preference for one variant over others, and, interestingly, this preference varies across different sign languages. For example, adult users of American Sign Language (ASL) and Al-Sayyid Bedouin Sign Language (ABSL) have a clear preference for perceptual variants, whereas users of New Zealand Sign Language (NZSL) are biased toward

\footnotetext{
${ }^{1}$ Note that similar ways of representing concepts have also been proposed for gestures accompanying speech (Müller, 2013), suggesting that these depictive strategies arise from basic affordances of the visual modality for representation (Masson-Carro et al., 2015; Perniss, Özyürek, \& Morgan, 2015).

2 The high incidence of different sign variants for the same concept has become more evident with the advent of corpus-based databases of sign languages. Examples of action and perceptual variants in BSL are BUS, BANANA, SHOES (http://bslsignbank.ucl.ac.uk/); in Auslan, BED, GLASSES, DOG (http://www.auslan.org.au/); in Sign Language of the Netherlands (NGT), BANANA (https://testsiteen.gebarencentrum.nl/).
} 
action-based signs (Padden et al., 2014). Based on the different patterns observed around the globe, researchers have proposed that sign languages can be classified into typological groups according to the referents they depict and the structural devices to represent them (Nyst, 2013; Padden et al., 2014). To date, however, lexical choice has only been studied in adult populations and in adultadult interactions. As such, it remains an empirical question whether deaf signing children have the same preferences as adults and whether their caregivers align their choices accordingly interacting with them.

Thus, in the present study, we ask whether the use of different types of iconic signs varies across age groups, and whether certain variants (action or perceptual-based signs) are preferred by children versus adults as well as when the communication is targeted for children. We aim to further our understanding on this issue by investigating patterns of usage of specific types of iconic signs by five groups of deaf users of TID: two groups of children (preschool and school-age), two groups of parents of the same children, and a separate group of adults.

\section{The Role of Iconicity in the Acquisition of Signed and Spoken Languages}

Over the last decade, a large body of research supporting the facilitative role of iconicity in language development has emerged. The abundance of sound-symbolic words in the emerging vocabularies of speaking infants is more prevalent than previously attested, and seem to contribute significantly in lexical acquisition (e.g., Laing, 2014). Additional supporting evidence has convincingly demonstrated that children as young as 25 months of age are sensitive to mimetic (iconic) verbs and take advantage of the sound-symbolic links to learn new words (Imai et al., 2008). This effect is not only present in infants acquiring a language rich in sound-symbolism, like Japanese - speakers of other languages are also sensitive to the iconic links between speech and referent and exploit them for vocabulary learning (Kantartzis et al., 2011; Revill et al., 2014). Compared with adults, toddlers use more sound-symbolic verbs over arbitrary ones despite both labels referring to the same motion event (Kita, Özyürek, Allen, \& Ishizuka, 2010; Yoshida, 2012). The bootstrapping hypothesis suggests that iconic symbols "help infants and toddlers initially to associate speech sounds with their referents to establish a lexical representation" (Imai \& Kita, 2014, p. 1).

Despite iconicity being much more pervasive in signed than in spoken languages, there has been some controversy on whether or how iconicity might play a role in sign language acquisition. The first studies investigating sign language acquisition do not report a facilitating effect of iconicity. Based on parental reports, Orlansky and Bonvillian (1984) followed the linguistic development of 11 deaf children acquiring ASL from birth (age range = four months to one year, two months) and found that they produced an equal proportion of iconic and arbitrary signs. Meier et al. (2008) investigated whether four deaf children acquiring ASL (age range = eight to seventeen months) had access to sign iconicity by assessing whether they enhanced signs' iconic features during spontaneous interactions with their caregivers. The authors did not find instances in which infants exaggerated any iconic properties of the sign (e.g., by licking their hand for the sign ICE-CREAM), and thus concluded that maturational constraints rather than iconic sign-form mappings drive sign language acquisition. The negligible effect of iconicity during sign acquisition was attributed to children not having sufficient world knowledge to make associations between a linguistic symbol and its referent (Newport \& Meier, 1985). The idea that iconicity takes time to learn was further corroborated in a study in which hearing children $(2 ; 5-5 ; 0)$ were asked to match an iconic sign with its referent (Tolar, Lederberg, Gokhale, \& Tomasello, 2008). Children younger than $2 ; 8$ performed below chance, but gradually improved in performance with age. At the earliest stages, children cannot make associations between an iconic (manual) form and its referent because this capacity gradually emerges in the preschool years (Namy, 2008).

Recent evidence, however, has shown that iconic signs are the first to be acquired by deaf children learning a sign language from their deaf parents (Thompson et al., 2012). Looking at parental reports of 31 deaf children learning BSL (age = eight to thirty-six months), the authors found that the first signs to be comprehended and produced were iconic, even when phonological complexity, frequency, and imageability was controlled for.

In this and earlier studies, however, iconicity has been defined in a broad sense when a more fine-grained operationalization of iconicity could better illuminate its role during lexical development. Some evidence suggests that, indeed, when we look at different types of iconic links between a sign and its referent, one can see an effect of iconicity in sign comprehension. In the sign-picture matching task described in the previous paragraph (Tolar et al., 2008), it was observed that signs depicting actions (e.g., the sign TOWEL represents a person pulling a towel sideto-side from behind) were the first and more accurately matched with their referent by children as young as $2 ; 8$. Thus, it is possible to expect that different types of iconicity may play a role at a developmental stage when the iconic links are available to children (3 years of age onward), and possibly that caregivers may align their lexical variant when interacting with children.

\section{Iconicity in Child-Directed Communication}

It is a well-established phenomenon that compared with adultto-adult communication, caregivers modify their behaviors during the interactions with their children. Child-directed speech, also called motherese, has features different from those present in the exchanges between adult conversational partners (Bornstein, Putnick, Cote, Haynes, \& Suwalsky, 2015; Bornstein et al., 1992). Child-directed speech often exaggerates intonation contours to emphasize characteristics of certain words (Herold, Nygaard, \& Namy, 2012), uses simplified vocabulary (Adi-Bensaid, BenDavid, \& Tubul-Lavy, 2015), and has higher pitch (Smith \& Trainor, 2008). An interesting modification in child-directed speech has been observed when parents favor sound-symbolic words when an arbitrary label is also possible. Japanese parents speaking to their children tend to use words that reflect iconic aspects of the referent (mimetic verbs) instead of less iconic labels (Nagumo, Imai, Kita, Haryu, \& Kajikawa, 2006; Yoshida, 2012). This trend diminishes substantially when parents interact with other adults.

Child-directed modifications are not exclusive to the spoken modality. There are reports that the iconic gestures produced by caregivers also serve as a communicative strategy through which 
children are capable of mapping new knowledge more easily. Campisi and Özyürek (2013) found that Italian adults use more iconic gestures when they were explaining how an instrument works to (an imagined) 12-year-old versus to an adult addressee. It has also been observed that around 26 months, English-speaking infants go through an iconic gesture spurt, which aligns with the time at which caregivers also increase the frequency and rate of their iconic gestures when communicating with their children (Özçalişkan \& Goldin-Meadow, 2011).

Another form of child-directed modification within the manual modality has been observed in sign languages. By means of repetition, avoidance of hand internal movements and displacement of locations, deaf parents alter their language to make signs more visually salient and facilitate acquisition (Holzrichter \& Meier, 2000; Masataka, 2000). Deaf children are more attentive to child-directed signing than to communication designed for deaf adults (Masataka, 2000). It is not known, however, whether iconicity plays a role in child-directed signing and, more specifically, whether caregivers modulate their choice of iconic lexical variant in their signing to deaf children.

\section{The Present Study}

Our study builds upon growing evidence on how iconic linguistic forms in both sign and speech may play a role in language development and in child-directed communication. It goes beyond previous studies, in that it investigates whether different types of iconic depictions might be favored by children and adults as well as by caregivers during development. Unlike previous studies that focused on 1 to 3 years, we target an age period (range $=$ three years, five months to nine years, ten months) when iconicity is considered to be accessible to children (Namy, 2008). To do so, we specifically look at children and adults' preferences for lexical items for which two iconic lexical variants exist for the same objects: one using representations akin to actions associated with the referent (action-based) and one with its perceptual features (perceptual-based). We specifically ask (a) Do signers of different age groups show a preference for one type of lexical variant when two variants are possible (action vs. perceptual)?; and (b) Do parents signing to their children choose a similar iconic depiction strategy as the one used by their children?

Based on studies showing that learning is easier when new forms overlap with previously known motor schemas (Yu, Smith, \& Pereira, 2008), we expect young signers to prefer lexical variants that represent objects through the resemblance with the actions associated with the referent (action-based variants). Emmorey's (2014) idea of iconicity as structure mapping would also support this prediction. In action-based variants, the hand represents the hand, and thus there is a high degree of structural overlap between a linguistic form (i.e., the sign) and motor/action knowledge related to the referent. In contrast, perceptual-based signs, although still iconic, have a lower degree of structural overlap because the hand does not represent the hand, but rather a part of the referent. Thus, the phonological form of perceptual-based variants has a more abstract relationship with the referent than action-based ones. This might lead to the expectation that children will prefer the latter over the former.

Furthermore, based on studies showing alignment in frequency and rate of the iconic gestures used by children (e.g., Özçalişkan \&
Goldin-Meadow, 2011), we expect parents' preferences to align with those of their children and differ from what is typical in adult-to-adult interactions. Finally, because there is no corpus-based data supporting the presence of lexical variants in TID, as in other sign languages (e.g., BSL, Auslan, Sign Language of the Netherlands), we also include a separate elicitation study by a different group of adult signers with the same target items to confirm that our iconic variants are lexical items of the TiD lexicon.

\section{Method}

The present data come from a larger data set investigating spatial descriptions by adult and child deaf signers of TİD (Sümer, 2015). In the task, participants described, from a picture, the spatial relationship (e.g., in, on, under) between two objects to elicit a target sign. For the purpose of this study, we focused only on the lexical items for which two lexical variants are available (i.e., action and perceptual). The reader can refer to the section Materials and Procedure for a full description of the stimulus materials.

\section{Participants}

Forty-eight deaf TID signers living in Istanbul, Turkey, were recruited for this study and were categorized into five groups: preschool children $(N=10$; mean age: five years, two months, $S D=13$ months, range $=$ three years, five months to six years, ten months); school-age children $(N=10$; mean age: eight years, three months, $S D=9$ months, range $=$ seven years, two months to nine years, ten months); the parents of the preschool children $(N=9)$; the parents of the school-age children $(N=9)$; and a different group of adults unrelated to the other groups $(N=10)$. All children were native TID signers and all adults were native or early signers (age of acquisition $=6$ years or younger). All participants had lived in Istanbul all their lives and were users of the same TID variant.

\section{Materials and Procedure}

Participants were instructed to describe the spatial relationship between two objects in a picture shown on a laptop. The computer screen was divided into four sections, with each quadrant displaying a picture with two toys placed in different spatial arrangements. The four pictures included the same two toys (e.g., a toy plane and a toy bed) in different spatial relationships (e.g., the plane was on, under, next to, or in front of the bed). In a self-paced task, participants pressed a key to bring the four pictures to the screen, with one of them being highlighted with a red frame (e.g., a plane under the bed). The red frame was indicative of the picture the participants had to describe to their interlocutor. Adults, preschool children, and school-age children described the picture to a deaf research assistant. Parents of preschool children and parents of school-age children described the pictures to their own children. They had not seen their children describing them to the deaf assistant. Interlocutors had a booklet with the same four pictures that the signer had for each description. After participants had described the highlighted picture, the interlocutor had to point at the correct picture on the booklet. The goal of the communicative exchange focused on the right type of spatial relation, as the objects were the same in all four pictures. 
From this data set, we selected objects for which signers used two lexical variants: an action and a perceptual variant. Actionbased signs represented objects through their resemblance to actions associated with the referent or the way an object is manipulated. Perception-based signs described the form of a referent by depicting its form with different hand configurations or by tracing its shape in space. ${ }^{3}$ The objects selected were toothbrush, cup, pen, bathtub, and bed, and each were described two, four, four, three, and three times, respectively, appearing in different spatial relations in the data set, making a total of 16 pictures. The objects used in the pictures were toys in a static position and did not show any agents performing an action on them.

\section{Coding and Data Analysis}

Each description was transcribed by a deaf assistant and later categorized into lexical signs labeling the objects in the picture and their corresponding classifier predicates. In the analysis, we included lexical signs only. ${ }^{4}$ With the help of a deaf TiD signer, we verified that the signs coded were lexical variants for the same object. After the analysis was carried out, a second coder, who is also a TID user, independently classified $20 \%$ of the data $(n=169$ descriptions out of 847) into action or perceptual variants to check for coding agreement. The interrater reliability for the two coders was found to be strong $(\kappa=0.769, p<.001,95 \%$ confidence interval [CI] [0.670, 0.868]).

In order to ensure that these variants were indeed part of the TID lexicon (i.e., not gestures or idiosyncratic sign productions), a separate post hoc elicitation and comprehension study with a different group of TID signers was carried out $(n=17$; five of them were native signers and the rest were exposed to TiD after 6 years of age). In the sign elicitation task, participants were shown pictures of the five objects used in the original study, but without the spatial relation as well as five filler pictures. The stimulus materials were generated from the pictures used in the picture description task, and using Photoshop, the nontarget items were removed so that they were presented in isolation. Participants were told that the aim of the task was to create a TID dictionary and that it was necessary to document all possible variants for each concept. Pictures were presented one at a time by an adult deaf research assistant and participants' responses were video recorded. We also included a sign comprehension task in which the same research assistant produced all the sign variants observed in the picture description task, one at a time, while participants were presented with two pictures of individual objects. One of the pictures referred to the sign produced by the research assistant. Participants were asked to select the picture of the sign observed but were explicitly told that it was also possible not to choose any picture if they thought the sign did not correspond to any of them. The sequence of the tasks was counterbalanced across participants.

\section{Results}

We calculated the proportions of action- and perceptual-based signs produced by counting the number of signs for each iconicity type divided by the total number of lexicalized signs produced for all the descriptions for each subject (see the online supplemental materials for examples). On the arcsine-transformed proportions of the action variants, we carried out linear mixed-effects models with crossed random effects using restricted maximum likelihood estimation. Age Group was the fixed factor (adults, preschool children, school-age children, parents of preschool children, and parents of school-age children), and random effects were participants, items, and age of acquisition (native vs. acquisition after 6 years of age). The partial effect of Age Group was significant. Preschool children $(M=0.81, S D=0.21)$ produced significantly more action variants than adults $(M=0.25, S D=0.14 ; \beta=$ $0.1110,95 \%$ CI $[0.073,0.148], p<.001)$. School-age children $(M=0.72, S D=0.12)$ also produced more action variants than adults $(\beta=0.0932,95 \%$ CI [0.056, 0.130], $p<.001)$. Similarly, compared with adults, preschool parents $(M=0.58, S D=0.28$; $\beta=0.0582,95 \%$ CI [0.013, 0.103], $p=.013)$ and school-age parents $(M=0.56, S D=0.19 ; \beta=0.0614,95 \%$ CI $[0.021$, $0.101], p=.003)$ produced significantly more action signs. Pairwise comparisons after Bonferroni corrections revealed there was no significant difference in the proportion of action signs produced by both groups of children, $t(9)=1.029, p=.330$. There was no difference in the proportion of action signs produced by preschool children and preschool parents, $t(8)=1.543, p=.161$. Similarly, school-age children did not differ from school-age parents, $t(8)=$ $1.606, p=.147$. Both groups of parents produced the same proportion of action signs, $t(8)=0.095, p=.927$. Partial effects of participant, item, age of acquisition, and interactions did not reach significance ( $p s>0.3$; see Figure 2).

Figure 3 shows the proportion of action signs produced per item in each group. As the statistical analysis on the random factors show, despite some variation, the same preferences hold for all the items: Adults produced few action signs when interacting with a deaf adult, but both groups of children and their parents favored the action variants more than adults.

We further looked at the markedness in the handshapes produced by participants to attest whether avoidance of phonologically complex signs explained the preference for action-based variants. In sign phonology, seven unmarked handshapes_ “绞,"

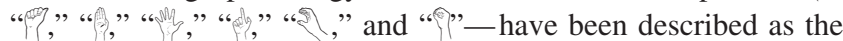
basic hand configurations from which more complex ones stem (Battison, 1978). These handshapes are the first to emerge in signing toddlers (Boyes-Braem, 1990), are present in all studied sign languages, and constitute a large proportion of signs in many lexicons (Johnston \& Schembri, 2007). We found a homogenous distribution of marked and unmarked handshapes across action and perceptual signs for all lexical variants (see Appendix B).

\footnotetext{
${ }^{3}$ Appendix A includes still images of the target lexical variants. Video clips of all signs are available in the online supplemental materials.

${ }^{4}$ In spatial descriptions, most sign languages use manual structures called classifier predicates, which follow lexicalized signs, and represent motion and location of referents. For instance, after introduction of lexical signs, an extended index finger on an open palm may represent a toothbrush or a man lying horizontally on a flat surface. All children and adults produced classifier predicates after the lexical signs and in similar frequency in the data from which the items for this study were selected (Sümer, 2015). Crucially, classifier predicates were not included in the analysis. In the current article, we followed a set of guidelines that have been previously used to distinguish lexical signs from classifier predicates in TiD and German Sign Language based on very similar data (Özyürek, Zwitserlood, \& Perniss, 2010; Perniss, Zwitserlood, \& Özyürek, 2015) and Sign Language of the Netherlands (Zwitserlood, 2003).
} 


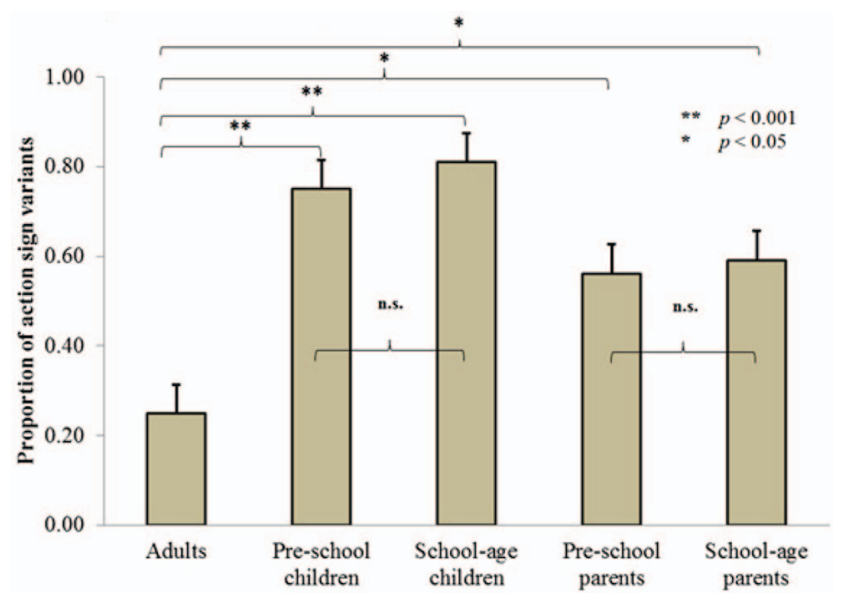

Figure 2. Proportion of action variants out of all signs across age groups. Bars represent standard error. See the online article for the color version of this figure.

We also investigated whether deaf parents exhibited another feature of child-directed signing, namely, repetition (Holzrichter \& Meier, 2000). More importantly, we looked at how they used this strategy with the different lexical variants. To that end, we calculated the instances in which adults (parents and adults) produced more than one sign for the same description. Of 159 signs produced, there were only two instances ( $1.2 \%$ of the adult signs) in which an adult repeated a sign in a description in signing to another adult. In contrast, there were 33 instances in preschool parents (17.6\% of a total of 188 signs) and 37 instances for school-age parents (18\% of 195 signs). We then calculated the sequence of signs for each repetition, that is, the sequence of iconic variants for each description (see Table 1).

When deaf parents produced a sign more than once, in the majority of cases, they repeated the same sign. This was consistent in both preschool and school-age parents (both approximately $60 \%$ ). To a lesser extent, both groups switched the lexical variant. In the case of preschool parents, it was more common that they

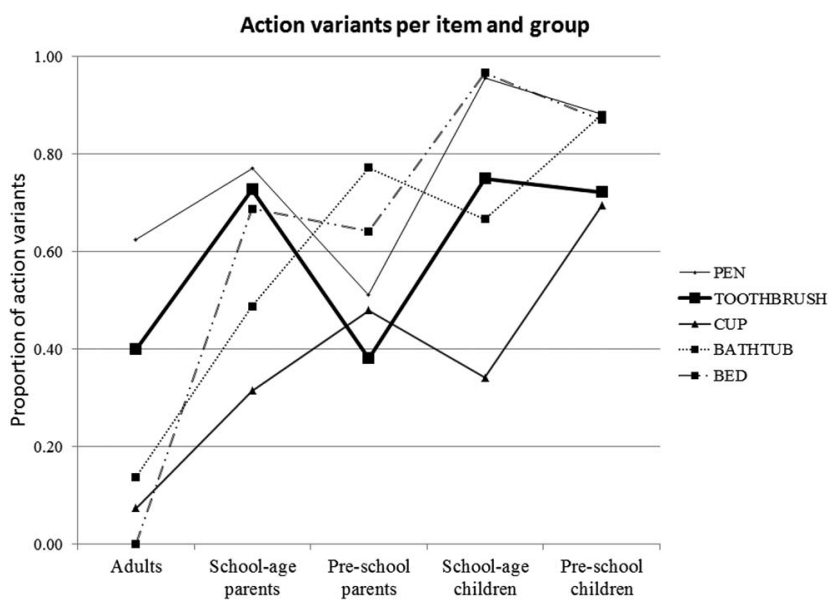

Figure 3. Proportion of action variants out of all signs per item for all age groups.
Table 1

Proportion of Instances When Parents Repeated a Sign for a Single Concept

\begin{tabular}{lcc}
\hline & \multicolumn{2}{c}{ Proportion of transitions } \\
\cline { 2 - 3 } Transition type & $\begin{array}{c}\text { Preschool parents } \\
(n=33 \text { signs })\end{array}$ & $\begin{array}{c}\text { School-age parents } \\
(n=37 \text { signs })\end{array}$ \\
\hline Perceptual-Action & .30 & .19 \\
Action-Perceptual & .10 & .22 \\
Same & .60 & .59 \\
Total & 1.00 & 1.00 \\
\hline
\end{tabular}

Note. This includes transitions from one type of lexical variant to another (perceptual to action or action to perceptual) or instances when parents repeated the same variant they produced initially.

started with a perceptual-based sign and then produced an actionbased sign (30\% of instances). In school-age parents, there was a more balanced split, with both transitions being almost as frequent. Statistical analysis on switches to a different variant (i.e., perceptual to action, and action to perceptual) revealed that only preschool parents had a significant inclination to produce an actionbased variant after they had produced a perceptual-based one $\left(\chi^{2}=18.10, d f=1, p<.001\right)$.

Finally, we report the data from the post hoc sign elicitation and comprehension task that would establish whether the variants used by the different groups were indeed part of the TiD lexicon. In the sign elicitation task, we found that $80 \%$ or more of participants produced both lexical variants for BATHTUB, CUP, and PEN. The action and the perceptual variants for BED were produced by $50 \%$ and $80 \%$ of the participants, respectively. The action and perceptual variants for TOOTHBRUSH were produced by $90 \%$ and $60 \%$ of participants, respectively. In the comprehension task, all participants chose the target picture $100 \%$ of the time for all the items. These data show that all variants coded in the picture description task for all groups of signers are permissible signs of the TiD lexicon (i.e., not gestures or idiosyncratic manual elaborations). ${ }^{5}$

\section{Discussion}

An interesting feature of sign languages is that signs for objects may have two iconic lexical variants: one representing an action associated with the referent, and the other one representing its perceptual features. Previous research has shown that these variants coexist in the signed lexicon, with adult signers showing preference of one variant over the other (Padden et al., 2014). In this study, we investigated, first, whether the two types of iconic depictions influence preference for a specific type of variant in

\footnotetext{
${ }^{5}$ The fact that some signs may look like some of the gestures used by the speaking community does not mean they are not part of a signed lexicon. Whereas some signs may have a gestural origin (Janzen \& Schaffer, 2002), the structural similarities between some iconic signs and iconic gestures should be attributed to the affordances of objects and the devices to depict them in the visual modality (Kendon, 2014; Masson-Carro et al., 2015; Padden et al., 2013, 2015; Perniss, Özyürek, et al., 2015). The results of the post hoc tasks confirm that these are possible lexical TiD variants regardless of their similarities with the gestures used by the surrounding speaking community. We do not, however, rule out the possibility that the sign forms that are initially preferred in sign language acquisition might be the ones that have similarities with gestural representations.
} 
deaf signing children from different age-groups when compared with deaf adults, and second, whether deaf parents' lexical choice during child-directed signing aligned to their children's.

We corroborated earlier findings in adult-adult interactions from other sign languages, in that TiD signers prefer one variant over the other (Padden et al., 2014, 2015). Adult TiD users favor mainly perceptual-based variants, at least for the five items we studied. This preference may be motivated by the typological properties of each individual sign language (e.g., NZSL uses action, whereas ASL, ABSL, and TID use perceptual variants). Interestingly, however, we found that action-based variants are preferred by both groups of children interacting with an adult. Caregivers interacting with their children also favored action-based variants, which is remarkable considering that the perceptual variant is the preferred form in adult-adult communication. Individual variation, age of sign exposure (nativeness) in caregivers, or specific items are unlikely to explain this effect because the partial effects of these factors accounted for a negligible proportion of the variance (less than $3 \%$ ).

The finding that deaf children have a preference for actionbased lexical variants fits well with the notion of iconicity as structure mapping (Emmorey, 2014). This idea posits that the more overlap there is between a phonological and a conceptual representation, the more iconicity will facilitate language processing and acquisition. In our study, action-based signs have a more direct structural mapping with the concept they represent because the hand represents the hand (e.g., the handshape "ro" in the action variant TOOTHRBRUSH represents a hand holding a toothbrush). In contrast, perceptual signs, although still iconic, do not have such direct structural mapping because the hand does not represent the hand (e.g., the handshape "हु " does not represent a finger, but rather the thin elongated form of a toothbrush). Perceptual signs have a higher level of abstraction, and children may require more cognitive maturity to make the relevant association. The distinction between action and perceptual signs reminds us that iconicity is not a categorical property of language, but rather lies within a continuum, with some signs being more transparent than others (Klima \& Bellugi, 1979; Pizzuto \& Volterra, 2000). Here, we argue that type of iconicity matters because action-based signs lie well within the transparent end of the continuum and, as such, are more directly (one-to-one) mapped to their referent, which explains children's preference during vocabulary development.

Deaf children's preference for action-based variants also goes in line with research in the development of children's co-speech gestures. When children (2-5 years) are prompted to produce the word for an object, they tend to accompany their spoken response with an iconic gesture that depicts the objects by the actions associated with it-like pretending to hold an umbrella while uttering the word umbrella (Stefanini, Bello, Caselli, Iverson, \& Volterra, 2009). This trend is not language-specific because a similar pattern was observed in Japanese and Italian toddlers performing the same task (Pettenati, Sekine, Congestrì, \& Volterra, 2012). Children's (40-60 months) fast-mapping of action gestures to object referents has been interpreted as actions being an easier type of gesture to process (Marentette \& Nicoladis, 2011). Tolar et al., (2008) also found that hearing children's ability to match iconic signs with their referent improved with age (two years, six months to five years of age), and, importantly, the first and most accurately recognized were signs for objects that referred to actions associated with them. These studies suggest that children acquiring a spoken language are biased toward manual forms representing body actions because they create a bridge between a linguistic label and children's action/motor experiences (Pettenati et al., 2012; Stefanini et al., 2009).

The parallels between sign and gesture development are not surprising given the overlaps in types of representations between both forms of manual communication. Whereas sign languages differ from each other in the preferred type of depictions they use for objects (e.g., ASL and ABSL: perceptual-based signs; NZSL: action-based signs; Padden et al., 2014), hearing people from different cultures have a clear tendency to produce action-based gestures when depicting objects that have affordances for manipulation (Masson-Carro, Goudbeek, \& Krahmer, 2015; Padden et al., 2015; van Nispen, van de Sandt-Koenderman, Mol, \& Krahmer, 2014). Thus, it is possible that during sign vocabulary development, signing children initially prefer sign variants that resemble the type of representations also preferred in gestures (i.e., action-based depictions).

The prevalence of gestures with action-based representations in speaking children has been explained by the link they create between a linguistic label and children's action/motor experiences (Pettenati et al., 2012; Stefanini et al., 2009). The literature on gesture and embodied cognition propose that gestural representations are mainly grounded in action/motor representations and are direct consequences of action simulations (Cook \& Tanenhaus, 2009; Hostetter \& Alibali, 2008). Within the realm of sign languages, the fact that the handshape of action-based signs represents the hand creates direct structural mappings between a linguistic form and a conceptual representation, thus facilitating signreferent associations (Emmorey, 2014). In other words, children might prefer action-based variants during vocabulary development because they provide a congruent link between a linguistic form and their action/motor experiences. This interpretation goes in line with studies demonstrating that language development is tightly linked to motor schemas (Yu \& Smith, 2012; Yu et al., 2008). This link may be particularly relevant to vocabulary development in sign-acquiring children who face the cognitive challenge of developing multiple lexical variants for the same concept.

We now move to sign productions by deaf parents. We found, first, that deaf parents use repetitions of the lexical items more often than in adult-to-adult interactions, a feature reported in child-directed communication (Holzrichter \& Meier, 2000). This shows that during interactions with children as old as 9 to 10 years, deaf caregivers might still employ features of child-directed signing. Interestingly, parents also showed a preference for actionbased signs during communication with children than in adult-toadult interactions. There are possible explanations for this effect. One is that parents might be aligning their variant or are primed by their children. Several studies have shown that parents modulate their own language based on their children's developing communicative skills. When children reach a linguistic milestone and start producing certain structures, their caregivers modify their own responses to align with them. In that sense, infants prompt their parents about their readiness to produce certain communicative structures, and, as a result, caregivers modify their language accordingly. This has been attested in vocalizations (Bornstein et al., 2015), pointing (Butterworth, 2003), object manipulations (Fukuyama et al., 2015), and iconic gestures (Özçalişkan \& GoldinMeadow, 2011). We deem likely that parents' inclination for action-based signs during child-directed signing can be attributed 
to their accommodating to the lexical variants used by their children. It is also possible that caregivers use iconicity as a communicative strategy and initially chose forms that ground representations to their children's action/motoric experience (Perniss \& Vigliocco, 2014). That is, parents may regard action-based signs more easily accessible to children.

Is it the case, then, that children's action-based preferences can be explained by the parental input rather than their bias for representations that map directly to their action/motoric experiences? Even though the design of our study does not allow us to completely refute the direct effects of input on children's' preference, we argue that this does not seem to be the case. First of all, even though not significant, children seem to have a greater bias for action-based signs than parents (see Figure 2). Furthermore, a post hoc analysis between action-based renditions in child-parent pairs revealed no significant correlation (Kendall's tau $=0.205, p=.091$ ). Even though not conclusive, this evidence is in line with the claim that deaf parents, rather than children, accommodate to their addressees. Paradigms in psycholinguistics investigating accommodation (e.g., priming in a communicative context between deaf parents and children) could be implemented in future research to investigate the source of this effect.

\section{Conclusion}

Our results go beyond recent claims about the effect of iconicity in sign and spoken language acquisition by showing, for the first time, that type of iconicity matters in sign learning and in child-directed signing. We suggest that children's preference for action-based variants reflect a general modality bias for communicative symbols relying on action/motor representations in communicating about objects, as also found in the development of co-speech gestures. This might be because of the close link between such representations in the manual/ visual and action/motor experience (Cook \& Tanenhaus, 2009; Hostetter \& Alibali, 2008). These findings open new avenues for further research in language and vocabulary development. Investigating different types and degrees of iconicity that exploit different perceptuomotor analogies may reveal important effects of iconicity in vocabulary learning in both signed and spoken languages.

\section{References}

Adi-Bensaid, L., Ben-David, A., \& Tubul-Lavy, G. (2015). Content words in Hebrew child-directed speech. Infant Behavior \& Development, 40, 231-241. http://dx.doi.org/10.1016/j.infbeh.2015.06.012

Akita, K. (2009). A grammar of sound-symbolic words in Japanese: Theoretical approaches to iconic and lexical properties of mimetics (Unpublished doctoral dissertation). Kobe University, Kobe, Japan.

Assaneo, M. F., Nichols, J. I., \& Trevisan, M. A. (2011). The anatomy of onomatopoeia. PLoS ONE, 6(12), e28317. http://dx.doi.org/10.1371/ journal.pone.0028317

Battison, R. (1978). Lexical borrowing in American Sign Language. Silver Spring, MD: Linstok Press.

Bornstein, M. H., Putnick, D. L., Cote, L. R., Haynes, O. M., \& Suwalsky, J. T. D. (2015). Mother-infant contingent vocalizations in 11 countries. Psychological Science, 26, 1272-1284. http://dx.doi.org/10.1177/ 0956797615586796

Bornstein, M. H., Tamis-LeMonda, C. S., Tal, J., Ludemann, P., Toda, S., Rahn, C. W., .. . Vardi, D. (1992). Maternal responsiveness to infants in three societies: The United States, France, and Japan. Child Development, 63, 808-821. http://dx.doi.org/10.2307/1131235

Boyes-Braem, P. (1986). Two aspects of psycholinguistic research: Ico- nicity and temporal structure. In B. Tervoort (Ed.), Signs of life: Proceedings of the Second European Congress on Sign Language Research. Amsterdam, the Netherlands: University of Amsterdam.

Boyes-Braem, P. (1990). Acquisition of the handshape in American Sign Language: A preliminary analysis. In V. Volterra \& C. J. Erting (Eds.), From gesture to language in hearing and deaf children (pp. 107-127). Washington, DC: Gallaudet University Press. http://dx.doi.org/10.1007/ 978-3-642-74859-2_10

Butterworth, G. (2003). Pointing is the royal road to language for babies. In S. Kita (Ed.), Pointing: Where language, culture, and cognition meet (pp. 9-29). New York, NY: Psychology Press.

Campisi, E., \& Özyürek, A. (2013). Iconicity as a communicative strategy: Recipient design in multimodal demonstrations for adults and children. Journal of Pragmatics, 47, 14-27. http://dx.doi.org/10.1016/j.pragma .2012.12.007

Cook, S. W., \& Tanenhaus, M. K. (2009). Embodied communication: Speakers' gestures affect listeners' actions. Cognition, 113, 98-104. http://dx.doi.org/10.1016/j.cognition.2009.06.006

Cuxac, C. (1999). French sign language: Proposition of a structural explanation by iconicity. Gesture-Based Communication in HumanComputer, 1739, 165-184. http://dx.doi.org/10.1007/3-540-46616-9_16

Dingemanse, M. (2011). The meaning and use of ideophones in Siwu. Nijmegen, the Netherlands: Radboud University.

Dingemanse, M., Blasi, D. E., Lupyan, G., Christiansen, M. H., \& Monaghan, P. (2015). Arbitrariness, iconicity, and systematicity in language. Trends in Cognitive Sciences, 19, 603-615. http://dx.doi.org/10.1016/j .tics.2015.07.013

Emmorey, K. (2001). Language, cognition, and the brain: Insights from sign language research. Mahwah, NJ: Erlbaum.

Emmorey, K. (2014). Iconicity as structure mapping. Philosophical Transactions of the Royal Society of London, Series B: Biological Sciences, 369, 20130301. http://dx.doi.org/10.1098/rstb.2013.0301

Fukuyama, H., Qin, S., Kanakogi, Y., Nagai, Y., Asada, M., \& MyowaYamakoshi, M. (2015). Infant's action skill dynamically modulates parental action demonstration in the dyadic interaction. Developmental Science, 18, 1006-1013. http://dx.doi.org/10.1111/desc.12270

Herold, D. S., Nygaard, L. C., \& Namy, L. L. (2012). Say it like you mean it: Mothers' use of prosody to convey word meaning. Language and Speech, 55, 423-436. http://dx.doi.org/10.1177/0023830911422212

Holzrichter, A., \& Meier, R. P. (2000). Child-directed signing in American Sign Language. In C. Chamberlain, J. Morford, \& R. Mayberry (Eds.), Language acquisition by eye (pp. 25-40). Mahwah, NJ: Erlbaum.

Hostetter, A. B., \& Alibali, M. W. (2008). Visible embodiment: Gestures as simulated action. Psychonomic Bulletin \& Review, 15, 495-514. http://dx.doi.org/10.3758/PBR.15.3.495

Imai, M., \& Kita, S. (2014). The sound symbolism bootstrapping hypothesis for language acquisition and language evolution. Philosophical Transactions of the Royal Society of London, Series B: Biological Sciences, 369, 20130298. http://dx.doi.org/10.1098/rstb.2013.0298

Imai, M., Kita, S., Nagumo, M., \& Okada, H. (2008). Sound symbolism facilitates early verb learning. Cognition, 109, 54-65. http://dx.doi.org/ 10.1016/j.cognition.2008.07.015

Janzen, T., \& Schaffer, B. (2002). Gesture as the substrate in the process of ASL grammaticization. In R. Meier, D. Quinto-Pozos, \& K. Cormier (Eds.), Modality and structure in signed and spoken languages (pp. 199-223). Cambridge, UK: Cambridge University Press. http://dx.doi .org/10.1017/CBO9780511486777.010

Johnston, T., \& Schembri, D. A. (2007). Australian Sign Language (Auslan): An introduction to sign language linguistics. Cambridge, UK: Cambridge University Press. http://dx.doi.org/10.1017/CBO9780511607479

Kantartzis, K., Imai, M., \& Kita, S. (2011). Japanese sound-symbolism facilitates word learning in English-speaking children. Cognitive Science, 35, 575-586. http://dx.doi.org/10.1111/j.1551-6709.2010.01169.x 
Kendon, A. (2014). Semiotic diversity in utterance production and the concept of "language." Philosophical Transactions of the Royal Society of London, Series B: Biological Sciences, 369, 20130293. http://dx.doi .org/10.1098/rstb.2013.0293

Kita, S., Özyürek, A., Allen, S., \& Ishizuka, T. (2010). Early links between iconic gestures and sound symbolic words: Evidence for multimodal protolanguage. In A. D. Smith \& M. B. Schouwstra (Eds.), Proceedings of the 8th International conference on the Evolution of Language (pp. 429-430). Singapore: World Scientific.

Klima, E., \& Bellugi, U. (1979). The signs of language. Cambridge, MA: Harvard University Press.

Laing, C. E. (2014). A phonological analysis of onomatopoeia in early word production. First Language, 34, 387-405.

Marentette, P., \& Nicoladis, E. (2011). Preschoolers' interpretations of gesture: Label or action associate? Cognition, 121, 386-399. http://dx .doi.org/10.1016/j.cognition.2011.08.012

Masataka, N. (2000). The role of modality input in the earliest stages of language acquisition: Studies of Japanese Sign Language. In C. Chamberlain, J. P. Morford, \& R. I. Mayberry (Eds.), Language acquisition by eye (pp. 3-24). Mahwah, NJ: Erlbaum.

Masson-Carro, I., Goudbeek, M., \& Krahmer, E. (2015). Can you handle this? The impact of object affordances on how co-speech gestures are produced. Language, Cognition and Neuroscience, 31, 430-440. http:// dx.doi.org/10.1080/23273798.2015.1108448

McNeill, D. (1992). Hand and mind: What gestures reveal about thought. Chicago, IL: University of Chicago Press.

Meier, R., Mauk, C. E., Cheek, A., \& Moreland, C. J. (2008). The form of children's early signs: Iconic or motoric determinants? Language Learning and Development, 4, 63-98. http://dx.doi.org/10.1080/15475 440701377618

Müller, C. (2013). Gestural modes of representation as techniques of depiction. In C. Müller, A. Cienki, S. Ladewig, D. McNeill, \& J. Bressem (Eds.), Body - language - communication: An international handbook on multimodality in human interaction (pp. 1687-1701). Berlin, Germany: De Gruyter Mouton

Nagumo, N., Imai, M., Kita, S., Haryu, E., \& Kajikawa, S. (2006). Sound iconicity bootstraps verb meaning acquisition. Paper Presented at the 15th International Conference of Infant Studies, Kyoto, Japan.

Namy, L. L. (2008). Recognition of iconicity doesn't come for free. Developmental Science, 11, 841-846. http://dx.doi.org/10.1111/j.14677687.2008.00732.x

Newport, E. L., \& Meier, R. P. (1985). The acquisition of American Sign Language. In D. Slobin (Ed.), The cross-linguistic study of language acquisition (Vol. 1, pp. 881-938). Mahwah, NJ: Erlbaum.

Nyst, V. (2013). Gesture as a blue print for sign language structure. Paper Presented at the Minerva Symposium on Emergent Languages and Cultural Evolution, Nijmegen, the Netherlands.

Oda, H. (2000). An embodied semantic mechanism for mimetic words in Japanese (Unpublished doctoral dissertation). Indiana University, Bloomington, Indiana.

Orlansky, M. D., \& Bonvillian, J. D. (1984). The role of iconicity in early sign language acquisition. Journal of Speech \& Hearing Disorders, 49, 287-292. http://dx.doi.org/10.1044/jshd.4903.287

Özçalişkan, S., \& Goldin-Meadow, S. (2011). Is there an iconic gesture spurt at 26 months? In G. Stam \& M. Ishino (Eds.), Integrating gestures: The interdisciplinary nature of gesture (pp. 163-174). Amsterdam, the Netherlands: John Benjamins.

Özyürek, A., Zwitserlood, I., \& Perniss, P. (2010). Locative expressions in signed languages: A view from Turkish Sign Language (TID). Linguistics, 48, 1111-1145. http://dx.doi.org/10.1515/ling.2010.036

Padden, C., Hwang, S.-O., Lepic, R., \& Seegers, S. (2015). Tools for language: Patterned iconicity in sign language nouns and verbs. Topics in Cognitive Science, 7, 81-94. http://dx.doi.org/10.1111/tops.12121
Padden, C., Meir, I., Hwang, S.-O., Lepic, R., Seegers, S., \& Sampson, T. (2014) Patterned iconicity in sign language lexicons. Gesture, 13, 287-305.

Perniss, P., Özyürek, A., \& Morgan, G. (2015). The influence of the visual modality on language structure and conventionalization: Insights from sign language and gesture. Topics in Cognitive Science, 7, 2-11. http:// dx.doi.org/10.1111/tops.12127

Perniss, P., Thompson, R. L., \& Vigliocco, G. (2010). Iconicity as a general property of language: Evidence from spoken and signed languages. Frontiers in Psychology, 1, 227.

Perniss, P., \& Vigliocco, G. (2014). The bridge of iconicity: From a world of experience to the experience of language. Philosophical Transactions of the Royal Society of London, Series B: Biological Sciences, 369, 20130300. http://dx.doi.org/10.1098/rstb.2013.0300

Perniss, P., Zwitserlood, I., \& Özyürek, A. (2015). Does space structure spatial language? A comparison of spatial expression across sign languages. Language, 91, 611-641. http://dx.doi.org/10.1353/lan.2015.0041

Pettenati, P., Sekine, K., Congestrì, E., \& Volterra, V. (2012). A comparative study on representational gestures in Italian and Japanese children. Journal of Nonverbal Behavior, 36, 149-164. http://dx.doi.org/10.1007/ s10919-011-0127-0

Pietrandrea, P. (2002). Iconicity and arbitrariness in Italian Sign Language. Sign Language Studies, 2, 296-321. http://dx.doi.org/10.1353/sls.2002 .0012

Pizzuto, E., \& Volterra, V. (2000). Iconicity and transparency in Sign Languages: A cross-linguistic cross-cultural view. In K. Emmorey \& H. L. Lane (Eds.), The signs of language revisited: An anthology to Honor Ursula Bellugi and Edward Klima (pp. 229-250). Mahwah, NJ: Erlbaum.

Revill, K. P., Namy, L. L., DeFife, L. C., \& Nygaard, L. C. (2014) Cross-linguistic sound symbolism and crossmodal correspondence: Evidence from fMRI and DTI. Brain and Language, 128, 18-24. http://dx .doi.org/10.1016/j.band1.2013.11.002

Smith, N., \& Trainor, L. J. (2008). Infant-directed speech is modulated by infant feedback. Infancy, 13, 410-420. http://dx.doi.org/10.1080/ 15250000802188719

Stamp, R., Schembri, A., Fenlon, J., Rentelis, R., Woll, B., \& Cormier, K. (2014). Lexical variation and change in British Sign Language. PLoS ONE, 9(4), e94053. http://dx.doi.org/10.1371/journal.pone.0094053

Stefanini, S., Bello, A., Caselli, M. C., Iverson, J. M., \& Volterra, V. (2009). Co-speech gestures in a naming task: Developmental data. Language and Cognitive Processes, 24, 168-189. http://dx.doi.org/10 1080/01690960802187755

Sümer, B. (2015). Acquisition of spatial language by signing and speaking children: A comparison of Turkish Sign Language (TID) and Turkish. Nijmegen, the Netherlands: Radboud University.

Taub, S. (2001). Language from the body: Iconicity and metaphor in American Sign Language. Cambridge, UK: Cambridge University Press. http://dx.doi.org/10.1017/CBO9780511509629

Thompson, R. L., Vinson, D. P., Woll, B., \& Vigliocco, G. (2012). The road to language learning is iconic: Evidence from British Sign Language. Psychological Science, 23, 1443-1448. http://dx.doi.org/10 $.1177 / 0956797612459763$

Tolar, T. D., Lederberg, A. R., Gokhale, S., \& Tomasello, M. (2008). The development of the ability to recognize the meaning of iconic signs. Journal of Deaf Studies and Deaf Education, 13, 225-240. http://dx.doi .org/10.1093/deafed/enm045

van Nispen, K., van de Sandt-Koenderman, M., Mol, L., \& Krahmer, E. (2014). Pantomime strategies: On regularities in how people translate mental representations into the gesture modality. In P. Bello, M. Guarini, M. McShane, \& B. Scassellati (Eds.), Proceedings of the 36th Annual Conference of the Cognitive Science Society (pp. 3020-3026). Austin, TX: Cognitive Science Society.

Vigliocco, G., Perniss, P., \& Vinson, D. (2014). Language as a multimodal phenomenon: Implications for language learning, processing and evolution. 
Philosophical Transactions of the Royal Society of London, Series B: Biological Sciences, 369, 20130292. http://dx.doi.org/10.1098/rstb.2013 .0292

Yoshida, H. (2012). A cross-linguistic study of sound-symbolism in children's verb learning. Journal of Cognition and Development, 13, 232265. http://dx.doi.org/10.1080/15248372.2011.573515

Yu, C., \& Smith, L. B. (2012). Embodied attention and word learning by toddlers. Cognition, 125, 244-262. http://dx.doi.org/10.1016/j.cognition .2012 .06 .016
Yu, C., Smith, L. B., \& Pereira, A. (2008). Grounding word learning in multimodal sensorimotor interaction. In B. C. Love, K. McRae, \& V. M. Sloutsky (Eds.), Proceeding of the 30th Annual Conference of the Cognitive Science Society (pp. 1017-1022). Austin, TX: Cognitive Science Society.

Zwitserlood, I. (2003). Classifying hand configurations in Nederlandse Gebarentaal (Sign Language of the Netherlands) (Unpublished doctoral dissertation). University of Utrecht, Utrecht, the Netherlands.

\section{Appendix A}

\section{Action and Perceptual-Based Lexical Variants in Turkish Sign Language (TID)}

\section{Appendix B}

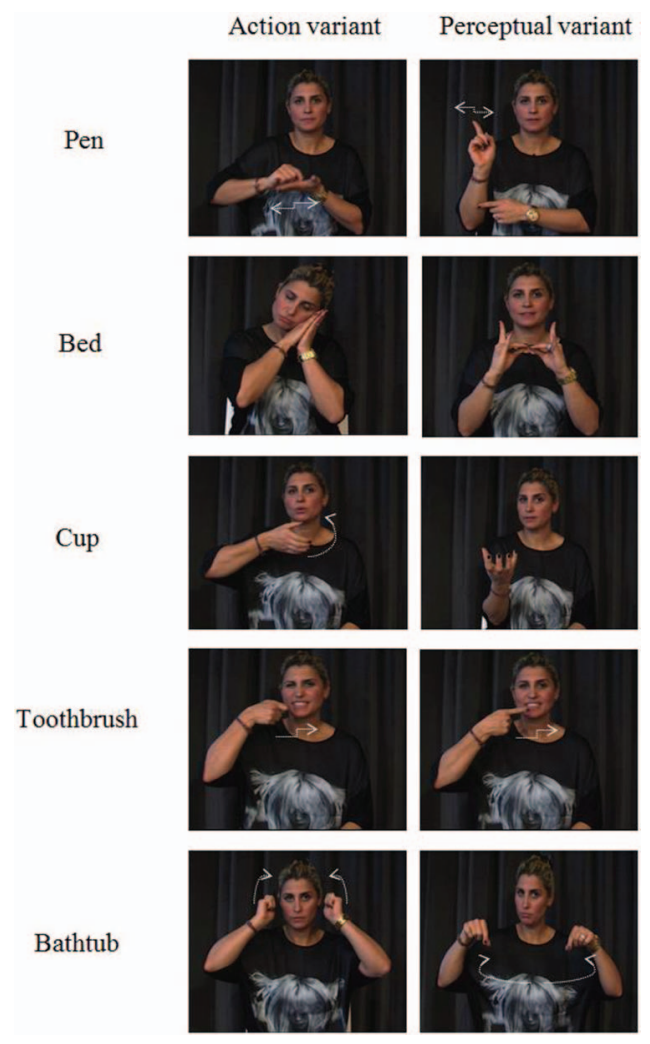

Copyright, 2016 by Asli Özyürek. The authors received signed consent from the person in the images to be published in this article. See the online article for the color version of this figure. 
Distribution of Marked and Unmarked Handshapes for Action and Perceptual-Based TID Variants

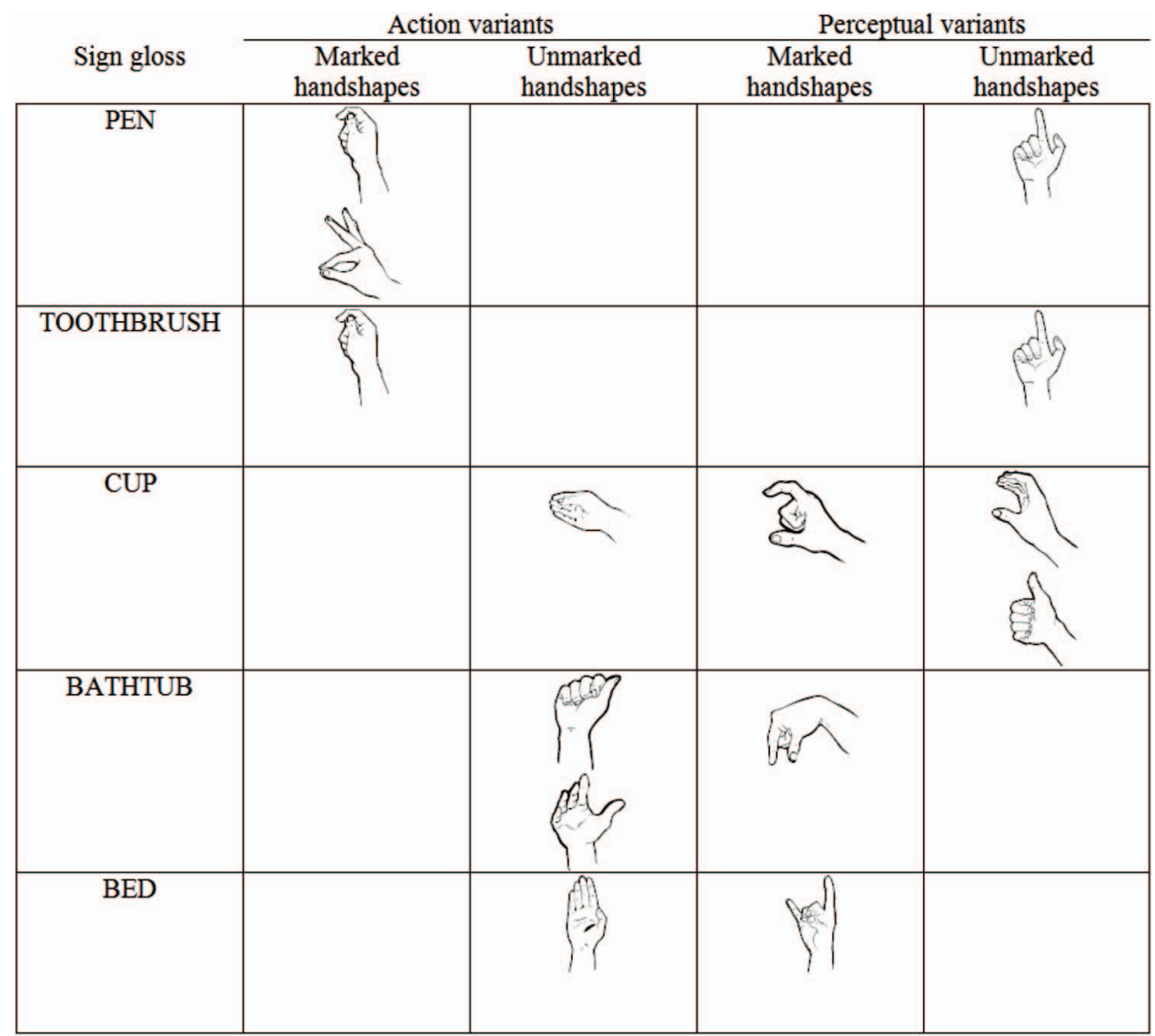

Received February 1, 2016 Revision received April 11, 2016 Accepted May 11, 2016 